\title{
Land of Strangers
}




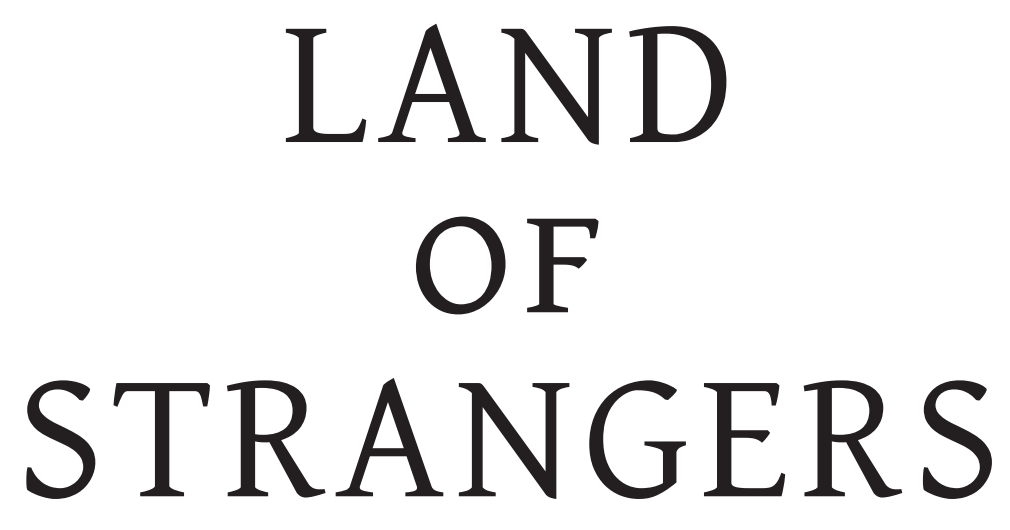

The Civilizing Project in Qing Central Asia

\title{
ERIC SCHLUESSEL
}


Columbia University Press

Publishers Since 1893

New York Chichester, West Sussex

cup.columbia.edu

Copyright $@ 2020$ Columbia University Press

All rights reserved

Library of Congress Cataloging-in-Publication Data

Names: Schluessel, Eric, author.

Title: Land of strangers : the civilizing project in Qing Central Asia / Eric Schluessel.

Description: New York : Columbia University Press, 2020. | Includes bibliographical references and index.

Identifiers: LCCN 2020010173 (print) | LCCN 2020010174 (ebook) | ISBN 9780231197540

(hardcover) | ISBN 9780231197557 (paperback) | ISBN 9780231552226 (ebook)

Subjects: LCSH: Xinjiang Uygur Zizhiqu (China)-History. | Xinjiang Uygur Zizhiqu

(China)-Ethnic relations. | Xinjiang Uygur Zizhiqu (China)-Politics and government. |

Uighur (Turkic people)-History. | China-Colonies-China-Xinjiang Uygur Zizhiqu. |

Asia, Central-Relations-China. | China-Relations-Asia, Central. |

China-History-Qing dynasty, 1644-1912.

Classification: LCC DS793.S62 .S35 2020 (print) | LCC DS793.S62 (ebook) | DDC 951/.6035-dc23

LC record available at https://lccn.loc.gov/2020010173

LC ebook record available at https://lccn.loc.gov/2020010174

Columbia University Press books are printed on permanent and durable acid-free paper.

Printed in the United States of America

Cover design: Milenda Nan Ok Lee

Cover image: Bilingual Chaghatay-Chinese document, dated 1928.

Photo by author. 
To Gwendolyn, who revels in the marginalia 
